
у взрослых больных муковисцидозом

1 - ФГБУ "НИИ пульмонологии" ФМБА России: 105077, Москва, ул. 11-я Парковая, 32, корп. 4;

2 - ГУ Медико-генетический научный центр РАМН: 115478, Москва, ул. Москворечье, 1

\title{
V.A.Samoylenko, N.V.Petrova, G.Yu.Babadzhanova, A.B.Nagornyy, S.A.Krasovskiy, A.G.Chuchalin A role of modifier gene TCF7L2 for development of diabetes in adult patients with cystic fibrosis
}

\begin{abstract}
Summary
Introduction. Patients with cystic fibrosis (CF) are in a high risk of a particular type of diabetes mellitus. The aim of this study was to investigate predictive factors for development of CF-related diabetes mellitus.

Methods. Allele and genotype frequencies of 3 gene transcription factor 7-like 2 (TCF7L2) polymorphisms (rs12255372, rs7903146, rs11196205) were investigated in adult patients with CF with or without carbohydrate metabolism disorders, in patients with diabetes mellitus and in controls. Results. Russian population of rs 12255372 polymorphism carriers is in a higher risk of diabetes development. Investigations of rs7903146 polimorphism of TCF7L2 showed that $\mathrm{C}$ allele frequency was higher than $\mathrm{T}$ allele frequency in all the patients' groups.

Conclusion. $\mathrm{C}$ allele and $\mathrm{C} / \mathrm{C}+\mathrm{C} / \mathrm{G}$ genotypes seemed to play a protective role and were related to lower risk of carbohydrate metabolism disorders in $\mathrm{CF}$ patients. On the contrary, $\mathrm{G}$ allele and $\mathrm{G} / \mathrm{G}$ homozygous genotype were related to $2.0-2.5$-fold increase in the risk of carbohydrate metabolism disorders.

Key words: cystic fibrosis, diabetes mellitus, carbohydrate metabolism disorders, allele, genotype, TCF7L2, polymorphisms.
\end{abstract}

\section{Резюме}

Изучена частота встречаемости аллелей и генотипов 3 полиморфизмов (rs12255372, rs7903146, rs11196205) в гене transcription factor 7-like 2 (TCF7L2) у взрослых больных муковисцидозом (MB) с нарушениями углеводного обмена (НУО), больных МВ без НУО, пациентов с сахарным диабетом 2-го типа (СД 2) и в группе контроля. Показано, что в российской популяции у носителей полиморфизма rs12255372 повышен риск развития СД 2. При исследовании полиморфизма rs7903146 гена TCF7L2 выявлено, что частота аллеля С преобладала над частотой аллеля Т во всех 4 группах. Не выявлено значимых различий в распределении частот аллелей и генотипов данного полиморфного маркера в исследуемых группах. Продемонстрировано, что наличие аллеля С и генотипов $\mathrm{C} / \mathrm{C}+\mathrm{C} / \mathrm{G}$ обусловливает протективный характер и снижение риска развития НУО у больных МВ. Напротив, при наличии аллеля $\mathrm{G}$ и гомозиготного генотипа $\mathrm{G} / \mathrm{G}$ риск развития НУО повышается в $2,0-2,5$ раза.

Ключевые слова: муковисцидоз, сахарный диабет, нарушения углеводного обмена, муковисцидоззависимый сахарный диабет, аллели, генотипы, ген TCF7L2, полиморфизмы: IVS3 C-T (rs7903146), IVS4 G-T (rs12255372), IVS3, G-C (rs11196205).

Муковисцидоз (МВ) (кистозный фиброз - cystic fibrosis) - генетически детерминированное аутосомнорецессивное заболевание, характеризующееся нарушением секреции экзокринных желез жизненно важных органов с преимущественным поражением дыхательной и пищеварительной систем, тяжелым течением и неблагоприятным прогнозом [1-3]. Считается, что 2,6-3,6 \% взрослого населения планеты являются гетерозиготными носителями гена МВ [4].

В последние десятилетия продолжительность жизни больных МВ неуклонно возрастает [5]. При этом увеличивается частота как легочных, так и внелегочных осложнений МВ, в т. ч. сахарного диабета (СД), составляя, по разным данным, 2,5-32\% [6-8].

О развитии при МВ особого типа диабета свидетельствуют данные ряда исследований $[9,10]$. Это также подтверждается изменением положения СД при МВ по классификации Всемирной организации здравоохранения (ВО3) по СД от 1985 и 1999 гг. Разница этих классификаций в том, что в 1-й (1985) СД при МВ рассматривается как мультифакторное заболевание, возможно, с сопряженными генетическими нарушениями, а во 2-й (1999) - как следствие органных поражений, которые возникают при МВ как отдельной нозологии [11, 12].

Для обозначения нарушений углеводного обмена (НУО) при МВ предлагается термин "муковисцидоззависимый сахарный диабет" (МЗСД) [13].

К настоящему времени выявлено 18 локусов, ассоциированных с риском возникновения СД 2-го типа (СД 2), большинство из которых - гены контроля клеточного цикла, транскрипционных факторов, ионных каналов, т. е. гены, продукты которых участвуют в секреции инсулина.

В недавних исследованиях о роли наследственных факторов в генезе МЗСД показана взаимосвязь некоторых полиморфизмов генов, в частности transcription factor 7-like 2 (транскрипционный клеточный фактор 7-й, сходный со 2-м - TCF7L2) с предрасположенностью к развитию МЗСД у больных MB. Так, S.M.Blackman et al. было проведено исследование наследственных факторов у близнецов и сибсов, в котором подтверждается вовлеченность генетических механизмов в развитие МЗСД [14]. 
Был выявлен ген предрасположенности к развитию CД 2. Им оказался TCF7L2, являющийся одним из генов предрасположенности к СД 2. При наличии семейного анамнеза СД 2 повышался риск развития СД в последующих поколениях больных МВ $(p=0,0009)$. Причем в исследовании семейного анамнеза при наличии гена TCF7L2 риск развития СД повышался в 3 раза $(p=0,0006)$, а средний возраст установления диагноза СД снижался до 7 лет. Таким образом, генетическая предрасположенность играет важную роль в определении риска развития СД у больных МВ.

Также имеются сообщения о связи полиморфизма гена TCF7L2 с предрасположенностью к развитию СД у больных МВ [15]. В работе D.Bodhini et al. уточнен вид полиморфизма гена TCF7L2 с наиболее выраженной ассоциацией с СД - Т-аллель $\operatorname{rs} 12255372(\mathrm{G} / \mathrm{T})$ и rs7903146(C/Т)-полиморфизмов [16].

В основе развития МЗСД лежит нарушение структуры островков Лангерганса поджелудочной железы (ПЖ), возникающее за счет фиброза и жирового перерождения ПЖ [17].

Предполагается, что МЗСД изначально является инсулинопеническим состоянием и характеризуется нарушением секреции инсулина вследствие недостаточности $\beta$-клеток $[18,19]$. Причем нарушение функции $\beta$-клеток появляется задолго до постановки диагноза СД и прогрессивно нарастает [20, 21].

О значении постепенного развития дефицита инсулина и инсулинорезистентности у больных МВ и СД свидетельствуют данные L.Dobson et al. [22].

Изложенное свидетельствует об актуальности изучения роли гена-модификатора TCF7L2 в возникновении МЗСД у взрослых больных МВ, а также особенностей патогенетических механизмов развития данного осложнения.

Целью работы явился анализ частоты встречаемости аллелей и генотипов 3 полиморфизмов IVS3 C-T (rs7903146), IVS4 G-T (rs12255372), IVS3, G-C (rs11196205) в гене TCF7L2 у взрослых больных МВ + НУО (МЗСД или с нарушенной толерантностью к глюкозе - НТГ) в группах больных МВ без НУО, СД 2 и контроля, а также оценка взаимосвязи изучаемых полиморфизмов и СД 2.

\section{Материалы и методы}

Пациенты, включенные в исследование, были рандомизированы на 4 группы: взрослые больные МВ + НУО (МЗСД и НТГ) $(n=47 ; 27$ и 20 больных соответственно); пациенты с МВ без НУО $(n=53)$; больные СД $2(n=48)$; контроль $(n=50)$.

У всех больных МВ диагноз устанавливался на основании клинической картины и подтверждался положительным потовым тестом и / или генотипированием.

Для идентификации мутаций CFTR выделение геномной ДНК у пациентов с МВ проводился из лейкоцитов венозной крови с использованием набора реактивов Wizard Genomic DNA Purification Kit (Promega, США) в соответствии с рекомендациями производителя. Анализ мутаций МВ проводился методом мультиплексной полимеразной цепной реакции (ПЦР) с последующим анализом длин амплифицированных фрагментов ДНК и образующихся гетеродуплексов.

Диагнозы МЗСД и НТГ у больных МВ, а также СД 2 устанавливались клинически врачом-эндокринологом в соответствии с критериями ВОЗ (1999).

Типирование 3 полиморфизмов в гене TCF7L2 (rs7903146, rs12255372, rs11196205) проведено методом ПЦР с последующей рестрикцией продуктов амплификации соответствующей эндонулеазой. Последовательности праймеров разработаны в лаборатории генетической эпидемиологии ГУ "Медикогенетический научный центр" РАМН.

Для выявления маркеров СД определялся С-пептид, аутоантитела (ААТ) к $\beta$-клеткам островков Лангерганса к инсулину, расчет индекса HOME-IR проводился по общепринятой методике.

Забор крови проводился натощак между 8:00 и 9:00 ч утра. Содержание С-пептида в сыворотке крови определялось методом иммуноферментного анализа (ИФА) с помощью наборов для ИФА ( $D R G$ Diagnostics $\mathrm{GmbH}$, Германия). Для качественного определения циркулирующих иммуноглобулинов (Ig) G-AAT к $\beta$-клеткам островков Лангерганса использовался набор для ИФА (Biomerica США). Для количественного определения Ig G-антител (АT) к инсулину использовался набор для ИФА (Orgentec Diagnostika GmbH, Германия).

Статистическая обработка результатов выполнена с использованием пакета программ для статистической обработки данных Statistica for Windows 7,0 (StatSoft, США). Для оценки различий в количественных показателях между выборками использовался метод Манна-Уитни. Определение достоверности различий между качественными показателями сравниваемых групп проводился с помощью критерия $\chi^{2}$. Различия считались достоверными при $p<0,05$.

Для описания относительного риска развития заболевания рассчитывалось отношение шансов (ОШ). Как отсутствие ассоциации рассматривалось ОШ = 1 , как положительная ассоциация - ОШ > 1, как отрицательная ассоциация аллеля или генотипа с заболеванием (пониженный риск развития патологии) считалось ОШ < 1. Доверительный интервал (ДИ) представляет собой интервал значений, в пределах которого с вероятностью $95 \%$ находится ожидаемое значение ОШ.

\section{Результаты исследования}

При сравнении антропометрических данных выявлено, что у больных СД 2 имеются значимо более высокие показатели индекса массы тела (ИМТ). Отмечено также, что больные СД 2 относятся к более старшей возрастной категории по сравнению с другими группами. У больных МВ + НУО и без НУО установлены более низкие показатели ИМТ, чем в группе контроля (табл. 1). 
Общая характеристика больных (генетическое исследование)

\begin{tabular}{l|c|c|c|c|}
\multicolumn{1}{|c|}{ Характеристика } & МВ + НУО, $n=47$ & МВ без НУО, $n=53$ & СД $2, n=48$ & Группа контроля, $n=50$ \\
Возраст, годы & $24,3 \pm 5,0$ & $25,3 \pm 5,2$ & $59,7 \pm 11,7^{*}$ & $23,7 \pm 4,9$ \\
Пол, м / ж & $21 / 26$ & $30 / 23$ & 22 & 28 \\
ИМТ, кг $/$ м $^{2}$ & $17,5 \pm 3,2$ & $18,5 \pm 2,4$ & $29,6 \pm 5,9^{* *}$
\end{tabular}

Примечание: * - p< 0,05 (СД 2 - МВ + НУО; МВ без НУО; группа контроля); ** - p<0,05 (СД 2 - МВ + НУО; МВ без НУО; группа контроля); *** $-p<0,05$ (группа контроля - МВ + НУО; МВ без НУО).

В табл. 2 представлена частота исследуемых аллелей и генотипов по кандидатному гену TCF7L2.

При исследовании распределения аллелей $\mathrm{G}$ и T полиморфизма rs12255372 гена TCF7L2 в 4 группах обнаружено, что лишь в группах СД 2 и контроля у частоты встречаемости аллелей и генотипов имелись достоверные различия (табл. 3).

При сравнительном анализе установлено снижение частоты аллеля $\mathrm{G}$ и возрастание аллеля $\mathrm{T}$ в группе СД 2 по сравнению с группой контроля. В группе СД 2 частота аллелей $\mathrm{G}$ и $\mathrm{T}$ полиморфизма rs12255372 гена TCF7L2 составила 0,656 и 0,344, а в группе контроля - 0,796 и 0,204 соответственно. Частота встречаемости генотипов $\mathrm{G} / \mathrm{G}$ и $\mathrm{T} / \mathrm{T}+\mathrm{G} / \mathrm{T}$ полиморфизма rs12255372 гена TCF7L2 в группе СД 2 составила 0,354 и 0,646 , а в группе контроля $-0,633$ и 0,367 соответственно.

Таким образом, риск развития СД 2 в российской популяции оказался связан с носительством аллеля Т $(\mathrm{OШ}=2,04 ; 95 \%$-ный ДИ $-1,07-3,90)$ и геноти- пов $\mathrm{G} / \mathrm{T}+\mathrm{T} / \mathrm{T}(\mathrm{OШ}=3,14 ; 95 \%$-ный ДИ - 1,37$7,20)$ полиморфизма rs12255372 гена TCF7L2. Аллель $\mathrm{G}(\mathrm{OШ}=0,49 ; 95 \%$-ный ДИ - 0,26-0,93) и генотип $\mathrm{G} / \mathrm{G}(\mathrm{OШ}=0,32 ; 95 \%$-ный ДИ -0,14-0,73) ассоциированы, напротив, с пониженным риском развития рассматриваемого заболевания.

Согласно полученным результатам частота аллеля С полиморфизма rs7903146 гена TCF7L2 преобладала над частотой аллеля $\mathrm{T}$ во всех 4 группах (см. табл. 2). Определение частоты аллелей Т и С показало минимальное значение аллеля С в группе СД 2 - 0,677 с дальнейшим увеличением и максимальным значением в группе контроля 0,770 и обратную динамику частоты встречаемости аллеля Т с 0,230 до 0,323 соответственно. При сравнительном анализе не выявлено значимых различий в распределении частот аллелей и генотипов данного полиморфного маркера во всех 4 группах.

При сравнении распределения частот аллелей и генотипов полимрофизма rs11196205 гена TCF7L2

Таблица 2

Исследуемые аллели и генотипы

\begin{tabular}{|c|c|c|c|c|c|}
\hline \multirow[t]{2}{*}{ Полиморфизм TCF7L2 } & \multirow[t]{2}{*}{ Аллели и генотипы } & \multicolumn{4}{|c|}{ Частота аллелей и генотипов } \\
\hline & & контроль, $n=50$ & МВ без НУО, $n=53$ & MB + HYO, $n=47$ & СД $2, n=48$ \\
\hline \multirow[t]{5}{*}{ rs12255372 (Mbol) } & G & $78 / 0,796$ & $78 / 0,736$ & $69 / 0,750$ & $63 / 0,656$ \\
\hline & $\begin{array}{ll}T \\
T\end{array}$ & $20 / 0,204$ & $28 / 0,264$ & $23 / 0,250$ & $33 / 0,344$ \\
\hline & $G / G$ & $31 / 0,633$ & $30 / 0,566$ & $26 / 0,565$ & $17 / 0,354$ \\
\hline & $G / T$ & $16 / 0,326$ & $18 / 0,340$ & $17 / 0,370$ & $29 / 0,604$ \\
\hline & $T / T$ & $2 / 0,041$ & $5 / 0,094$ & $3 / 0,065$ & $2 / 0,042$ \\
\hline \multirow[t]{5}{*}{ rs11196205 (Mspl) } & C & $44 / 0,440$ & $58 / 0,558$ & $37 / 0,394$ & $47 / 0,490$ \\
\hline & G & $56 / 0,560$ & $46 / 0,442$ & $57 / 0,606$ & $49 / 0,51$ \\
\hline & $C / C$ & $8 / 0,160$ & $16 / 0,308$ & $8 / 0,170$ & $10 / 0,208$ \\
\hline & $G / C$ & $28 / 0,560$ & $26 / 0,500$ & $21 / 0,447$ & $27 / 0,563$ \\
\hline & G/G & $14 / 0,280$ & $10 / 0,192$ & $18 / 0,383$ & $11 / 0,223$ \\
\hline \multirow[t]{5}{*}{ rs7903146 (Msel) } & C & $77 / 0,770$ & $79 / 0,745$ & $68 / 0,727$ & $65 / 0,677$ \\
\hline & $T$ & $23 / 0,230$ & $27 / 0,255$ & $26 / 0,273$ & $31 / 0,323$ \\
\hline & $C / C$ & $29 / 0,580$ & $31 / 0,585$ & $24 / 0,511$ & $19 / 0,396$ \\
\hline & $\mathrm{C} / \mathrm{T}$ & $19 / 0,380$ & $17 / 0,321$ & $20 / 0,426$ & $27 / 0,563$ \\
\hline & $T / T$ & $2 / 0,04$ & $5 / 0,094$ & $3 / 0,063$ & $2 / 0,042$ \\
\hline
\end{tabular}

Таблица 3

TCF7L2 (полиморфизм rs12255372)

\begin{tabular}{|c|c|c|c|c|c|}
\hline \multirow[t]{2}{*}{ Аллели и генотипы } & \multicolumn{2}{|c|}{ Частота аллелей и генотипов } & \multirow[t]{2}{*}{$p$} & \multirow[t]{2}{*}{ ош } & \multirow[t]{2}{*}{ 95\%-ный дИ } \\
\hline & СД $2, n=48$ & контроль, $n=50$ & & & \\
\hline G & $63 / 0,656$ & $78 / 0,796$ & 0,03 & 0,49 & $0,26-0,93$ \\
\hline $\mathrm{T}$ & $33 / 0,344$ & $20 / 0,204$ & - & 2,04 & $1,07-3,90$ \\
\hline $\mathbf{G} / \mathbf{G}$ & $17 / 0,354$ & $31 / 0,633$ & 0,006 & 0,32 & $0,14-0,73$ \\
\hline $\mathrm{G} / \mathrm{T}+\mathrm{T} / \mathrm{T}$ & $31 / 0,646$ & $18 / 0,367$ & - & 3,14 & $1,37-7,20$ \\
\hline
\end{tabular}


достоверно значимые различия получены в группах МВ без НУО и МВ + НУО соответственно (табл. 4).

При определении частот аллелей $\mathrm{C}$ и $\mathrm{G}$ показано, что в группе МВ без НУО они составили 0,558 и 0,442 , а в группе МВ + НУО - 0,394 и 0,606 соответственно. При оценке распределения частот генотипов выявлено, что генотипы $\mathrm{C} / \mathrm{C}+\mathrm{C} / \mathrm{G}$ и $\mathrm{G} / \mathrm{G}$ полимрофизма rs11196205 гена TCF7L2 составили в группе больных МВ без НУО 0,808 и 0,192, а в группе $\mathrm{MB}+\mathrm{HУO} \mathrm{-} \mathrm{0,617} \mathrm{и} \mathrm{0,383} \mathrm{соответственно.} \mathrm{Со-}$ гласно полученным данным, наличием аллеля $\mathrm{C}$ $(\mathrm{OШ}=0,51 ;$ ДИ $-0,29-0,91)$ и генотипов $\mathrm{C} / \mathrm{C}+\mathrm{C} / \mathrm{G}$ $(\mathrm{OШ}=0,38 ; 95 \%$-ный ДИ - 0,15-0,95) обусловлены протективный характер и снижение риска развития НУО у больных МВ. Напротив, при наличии аллеля $\mathrm{G}(\mathrm{OШ}=1,94 ; 95 \%$-ный ДИ $-1,10-3,42)$ и гомозиготного генотипа $\mathrm{G} / \mathrm{G}(\mathrm{OШ}=2,61 ; 95 \%$-ный ДИ $1,05-6,45)$ риск развития НУО повышается в 2,0-2,5 раза.

При дальнейшем сравнительном анализе распределения частот аллелей и генотипов полиморфизма rs11196205 гена TCF7L2 в группах MB без НУО и подгруппах больных МЗСД, входящих в группу МВ + НУО, получены аналогичные результаты (табл. 5).

Для выявления маркеров СД и уточнения характера возникающих НУО во всех 4 группах определялись С-пептид, ААТ к клеткам островков Лангерганса, АAТ к инсулину, расчет индекса HOMA-IR. Полученные результаты представлены в табл. 6 .

Показано, что в группе больных МВ + НУО отмечен достоверно более высокий уровень АТ к инсули- ну в сравнении с группой контроля - это максимальный показатель для всех изучаемых групп. Данный результат вполне ожидаем, т. к. терапия МЗСД предполагает назначение инсулинотерапии с момента постановки диагноза МЗСД, что ведет к образованию АТ к экзогенному инсулину.

Во всех 4 группах отмечен низкий уровень AT к $\beta$-клеткам ПЖ. Но в группах МВ + НУО и контроля этот показатель практически одинаков. Это говорит о том, что риск возникновения СД 1 у больных МВ + НУО не превышает популяционный риск развития СД 1.

Уровень С-пептида снижен во всех группах за исключением группы контроля, что подтверждается постепенным снижением функции $\beta$-клеток ПЖ и выработки инсулина вследствие метаболических нарушений, связанных, вероятно, с поражением островков Лангерганса.

Чувствительность к инсулину у больных МВ + НУО и без НУО практически аналогична показателям в группе сравнения.

\section{Обсуждение}

Точностью и своевременностью установления диагноза определяется качество оказываемой медицинской помощи и проведение необходимых профилактических мероприятий по своевременному выявлению и предупреждению заболевания в группах повышенного риска. Частота заболеваемости МЗСД среди больных МВ в некоторых популяциях достигает $50 \%$, что, по всей видимости, связано с увеличением про-

Таблица 4

TCF7L2 (полиморфизм rs11196205)

\begin{tabular}{|c|c|c|c|c|c|}
\hline \multirow[t]{2}{*}{ Аллели и генотипы } & \multicolumn{2}{|c|}{ Частота аллелей и генотипов } & \multirow[t]{2}{*}{$p$} & \multirow[t]{2}{*}{ ОШ } & \multirow[t]{2}{*}{ 95\%-ный дИ } \\
\hline & MB + HYO, $n=47$ & МВ без НУО, $n=53$ & & & \\
\hline C & $37 / 0,394$ & $58 / 0,558$ & 0,02 & 0,51 & $0,29-0,91$ \\
\hline G & $57 / 0,606$ & $46 / 0,442$ & - & 1,94 & $1,10-3,42$ \\
\hline $\mathrm{C} / \mathrm{C}+\mathrm{C} / \mathrm{G}$ & $29 / 0,617$ & $42 / 0,808$ & 0,04 & 0,38 & $0,15-0,95$ \\
\hline $\mathbf{G} / \mathbf{G}$ & $18 / 0,383$ & $10 / 0,192$ & - & 2,61 & $1,05-6,45$ \\
\hline
\end{tabular}

Таблица 5

TCF7L2 (полиморфизм rs11196205)

\begin{tabular}{|c|c|c|c|c|c|}
\hline \multirow[t]{2}{*}{ Аллели и генотипы } & \multicolumn{2}{|c|}{ Частота аллелей и генотипов } & \multirow[t]{2}{*}{$p$} & \multirow[t]{2}{*}{ ОШ } & \multirow[t]{2}{*}{ 95\%-ный дИ } \\
\hline & МЗСД, $n=27$ & МВ без НУО, $n=53$ & & & \\
\hline C & $19 / 0,352$ & $58 / 0,558$ & 0,01 & 0,43 & $0,22-0,85$ \\
\hline G & $35 / 0,648$ & $46 / 0,442$ & & 2,32 & $1,18-4,58$ \\
\hline$C / C+C / G$ & $15 / 0,556$ & $42 / 0,808$ & 0,02 & 0,30 & $0,11-0,83$ \\
\hline G/G & $12 / 0,444$ & $10 / 0,192$ & & 3,36 & $1,20-9,37$ \\
\hline
\end{tabular}

Таблица 6

Маркеры СД

\begin{tabular}{|c|c|c|c|c|}
\hline Маркер & $\mathrm{MB}+\mathrm{HYO}, n=47$ & МВ без НУО, $n=53$ & СД 2, $n=48$ & Контроль, $n=50$ \\
\hline АТ к инсулину, ЕД / мл & $2,69 \pm 6,87^{*}$ & $1,74 \pm 4,34$ & $1,46 \pm 3,79$ & $0,83 \pm 0,88$ \\
\hline АТ к $\beta$-клеткам & $0,12 \pm 0,33$ & $0,20 \pm 0,40$ & 0 & $0,1 \pm 0,31$ \\
\hline С-пептид, нг / мл & $2,12 \pm 1,13^{* *}$ & $3,31 \pm 2,71$ & $2,89 \pm 2,51$ & $3,82 \pm 2,09$ \\
\hline HOME-IR & $2,747 \pm 2,965$ & $2,747 \pm 2,625$ & - & $3,508 \pm 2,876$ \\
\hline
\end{tabular}

Примечание: * $-p<0,05$ (контроль - МВ + НУО); ** $-p<0,05$ (контроль - МВ + НУО). 
должительности их жизни [23]. В российской популяции среди пациентов с МВ распространенность НУО составила 50,9 \% [24]. Учитывая значительный прогресс в оказании медицинской помощи, в российской популяции следует ожидать увеличения продолжительности жизни и роста заболеваемости МЗСД среди пациентов с МВ. Определенные трудности возникают при своевременном выявлении НУО среди пациентов с МВ, т. к. нередко имеется длительный доклинический период, аналогичный СД 2. Такой простой и дотупный метод скрининга, как определение гликированного гемоглобина, на сегодняшний день не рекомендован для данной группы пациентов (ADA, 2013). Поэтому в ряде стран всем пациентам с МВ в возрасте старше 10 лет проводится оральный тест НТГ. Знание генетических, биохимических и фенотипических маркеров МЗСД значительно облегчает эту задачу и позволяет своевременно назначить необходимую терапию. На сегодняшний день четкие клинические рекомендации по оптимальной сахароснижающей терапии у больных МЗСД отсутствуют. Во многих медицинских центрах изучаются возможности как терапии пероральными сахароснижающими препаратами, так и более раннего (до повышения гликемии выше пороговых значений) назначения инсулина. В российской популяции пациентам с МЗСД терапия инсулином назначается в кратчайшие сроки после установления диагноза согласно критериям ВО3. В данном исследовании предпринята попытка изучения некоторых из возможных маркеров МЗСД и, по мере возможности - обоснования принципов сахароснижающей терапии.

Анализ антропометрических данных (низкий ИМТ) и молодой возраст, в котором у пациентов с МВ развиваются нарушения углеводного обмена, позволяют заподозрить СД 1. Однако частота встречаемости иммунологических маркеров СД 1 (АТ к $\beta$-клеткам) среди пациентов с МЗСД не отличается от группы контроля, что свидетельствует о том, что заболеваемость СД 1 среди лиц с МВ не превышает заболеваемость СД 1 в российской популяции. Достоверное увеличение встречаемости АТ к $\beta$-клеткам среди пациентов М3 + НУО вполне ожидаемо, т. к. все пациенты с МЗСД получают терапию инсулином.

По результатам данного исследования установлено, что уровень HOMA-IR в группах пациентов и с MB, и с МЗСД не превышает 2,7 и достоверно не отличается от показателей в группе здорового контроля. Таким образом, при выборе сахароснижающей терапии не стоит использовать препараты, улучшающие чувствительность к инсулину (метформин и глитазон).

Снижение уровня C-пептида и иммунореактивного инсулина в группе МВ + НУО подтверждается результатами других исследований [25] и позволяет трактовать МЗСД как инсулинопеническое состояние. В настоящее время снижение секреторной возможности ПЖ и развитие МЗСД расценивается как результат дегенеративных процессов на фоне основ- ного заболевания. Согласно результатам данного исследования показано возможное участие гена TCF7L2 в формировании МЗСД у больных MB, т. к. его продукт - транскрипционный фактор, по литературным данным, контролирует экспрессию ряда генов, вовлеченных в регуляцию метаболизма глюкозы [26, 27].

Установлено, что в частоте распределения аллелей $\mathrm{G}$ и Т и их генотипов полиморфизма rs 12255372 гена TCF7L2 имелись достоверные различия лишь в группах СД 2 и контроля. Показано как снижение частоты аллеля $\mathrm{G}$, так и возрастание аллеля T в группе СД 2 в сравнении с группой контроля. Частота аллелей $\mathrm{G}$ и Т данного полиморфизма в группе СД 2 составила 0,656 и 0,344 , а в группе контроля $-0,796$ и 0,204 соответственно. Частота генотипов $\mathrm{G} / \mathrm{G}$ и $\mathrm{T} / \mathrm{T}+\mathrm{G} / \mathrm{T}$ полиморфизма rs12255372 в группе СД 2 составила 0,354 и 0,646 , в группе контроля $-0,633$ и 0,367 соответственно.

В российской популяции риск развития СД 2 связан с носительством аллеля Т (ОШ $=2,04 ; 95 \%$-ный ДИ - 1,07-3,90) и генотипов G/T + T/Т (ОШ = 3,14; 95\%-ный ДИ - 1,37-7,20) полиморфизма rs 12255372 гена TCF7L2. Аллель G (OШ = 0,49; 95\%-ный ДИ $0,26-0,93)$ и генотип $\mathrm{G} / \mathrm{G}(\mathrm{OШ}=0,32 ; 95 \%$-ный ДИ - 0,14-0,73), напротив, ассоциированы с пониженным риском развития рассматриваемого заболевания.

При исследовании полиморфизма rs7903146 гена TCF7L2 выявлено, что частота аллеля T преобладала над частотой аллеля С во всех 4 группах. При сравнительном анализе не выявлено значимых различий в распределении частоты аллелей и генотипов данного полиморфного маркера в исследуемых группах.

Полученные данные согласуются с результатами других исследований. Первое и единственное исследование полиморфизма гена TCF7L2 в российской популяции проведено Е.В.Бирюковой (2009) среди 204 жителей Москвы с метаболическим синдромом. Выявлено достоверное снижение секреции инсулина на нагрузку глюкозой и повышение риска СД 2 у носителей аллеля G/T гена TCF7L2. Аналогичные результаты получены в датской, индийской и исландской популяциях, но в этих исследованиях показано, что данный риск связан с полиморфизмом как rs12255372, так и rs7903146 [28-30]. В данном исследовании эта зависимость выявлена лишь в отношении полиморфизма rs12255372.

При изучении полиморфизма rs11196205 гена TCF7L2 выявлено снижение частоты аллеля C и повышение частоты аллея $\mathrm{G}$ в группе больных $\mathrm{MB}+$ НУО. Распределение частоты генотипов оказалось следующим: генотипы $\mathrm{C} / \mathrm{C}+\mathrm{C} / \mathrm{G}$ и $\mathrm{G} / \mathrm{G}$ составили в группе больных МВ без НУО 0,808 и 0,192, а в группе МВ + НУО - 0,617 и 0,383 соответственно. Учитывая полученные результаты, можно сделать вывод, что наличие аллеля С (ОШ $=0,51 ; 95 \%$-ный ДИ 0,29-0,91) и генотипов $\mathrm{C} / \mathrm{C}+\mathrm{C} / \mathrm{G}(\mathrm{OШ}=0,38$; 95\%-ный ДИ - 0,15-0,95) обусловливает протективный характер, снижая риск развития НУО у больных МВ и наоборот. В настоящее время в литературе, 
посвященной изучению гена TCF7L2, протективная роль аллеля С не обсуждалась. Данное наблюдение расценивается как особенность российской популяции, требуется дальнейшее уточнение и изучение.

Наличие аллеля $\mathrm{G}(\mathrm{OШ}=1,94 ; 95 \%$-ный ДИ $1,10-3,42)$ и гомозиготного генотипа $\mathrm{G} / \mathrm{G}(\mathrm{OШ}=2,61$; 95\%-ный ДИ - 1,05-6,45) повышает риск развития НУО в 2,0-2,5 раза. Больные МВ с данным полиморфизмом должны находиться под более пристальным наблюдением эндокринолога. Контроль гликемии как натощак, так и после гликемической нагрузки должен проводиться с первых лет жизни. Более раннее начало терапии инсулином в молодом возрасте позволит предупредить отставание в физическом развитии больных (рост, масса тела) и улучшить функциональные показатели легочной функции.

\section{Заключение}

Определение ассоциации гена с заболеванием и последующая оценка индивидуального генетического риска имеют значение для разработки эффективных методов профилактики и лечения данной патологии, а также ее осложнений в зависимости от наследственной предрасположенности конкретного больного. Выявление аллельных вариантов полиморфных маркеров различных генов-кандидатов, обусловливающих повышенный генетический риск развития МЗСД, создает основу для разработки дифференцированного подхода к профилактике и лечению, а также диагностических методов прогнозирования течения этого заболевания.

Учитывая полученные результаты, можно сделать следующие выводы:

- В российской популяции у носителей полиморфизма rs12255372 повышен риск развития СД 2.

- У больных МВ - носителей полиморфизма rs11196205 с аллелем С (и генотипов C/C + C/G) понижен риск развития МЗСД (т. е. данный полиморфизм играет протективную роль), наличие же полиморфизма rs11196205 с аллелем G (и гомозиготного генотипа $G / G$ ) указывает на более чем 2-кратное повышение риска развития МЗСД у его носителей.

- Риск развития СД 1 у больных МВ + НУО не превышает популяционный риск развития СД 1.

- Больные МВ имеют меньшие значения выработки инсулина, о чем свидетельствует уровень С-пептида, что, очевидно, связано с метаболическими процессами и поражением островков Лангерганса.

- Инсулинорезистентности у больных МВ + НУО и без НУО не выявлено, о чем свидетельствует сравнимая чувствительность к инсулину в 2 группах и в группе контроля.

\section{Литература / References}

1. Капранов Н.И. Эпидемиология, клинико-генетические особенности, лечение и реабилитация больных муковисцидозом. Российский вестник перинатологии и пе- диатрии. 1997; 2: 16-23. / Kapranov N.I. Epidemiology, clinical and genetic features, treatment and rehabilitation of cystic fibrosis patients. Rossiyskiy vestnik perinatologii i pediatrii. 1997; 2: 16-23 (in Russian).

2. Капранов Н.И. Муковисцидоз. Российский журнал гастроэнтерологии, гепатологии, колонопроктологии. 2000; 1: 62-66. / Kapranov N.I. Cystic fibrosis. Rossiyskiy zhurnal gastroenterologii, gepatologii, kolonoproktologii. 2000; 1: 62-66 (in Russian).

3. Davis P.B. Cystic Fibrosis Since 1938. Am. J. Respir. Crit. Care Med. 2006; 173: 475-482.

4. Самильчук Е.И., Чучалин А.Г. Гетерозиготность по мутации дельта F580 гена муковисцидоза среди больных с хронической обструктивной патологией органов дыхания. Пульмонология. 1994; 3: 47-50. / Samilchuk E.I., Chuchalin A.G. Heterozygosity for delta F580 gene mutations in patients with chronic obstructive respiratory disease. Pul'monologiya. 1994; 3: 47-50 (in Russian).

5. Красовский С.А., Черняк А.В., Амелина Е.Л. и др. Динамика выживаемости больных муковисцидозом в Москве и Московской области за периоды 1992-2001 и 2002-2011 гг. Пульмонология. 2012; 3: 79-86. / Krasovskiy S.A., Chernyak A.V., Amelina E.L. et al. Survival dynamics in cystic fibrosis patients in Moscow and Moscow region in 1992-2001 and 2002-2011. Pul'monologiya. 2012; 3: 79-86 (in Russian).

6. Fischman D., Nookala V.K. Cystic fibrosis-related diabetes mellitus: etiology, evaluation, and management. Endocr. Pract. 2008; 14 (9): 1169-1179.

7. MacDonald A., Holden C., Harris G. Nutritional strategies in cystic fibrosis: current issues. J. Roy. Soc. Med. 1991; 84 (18): $28-35$

8. Красовский С.А., Никонова В.С., Каширская Н.Ю. и др. Клинико-генетическая, микробиологическая и функциональная характеристика больных муковисцидозом, проживающих в Москве и Московской области. Вопросы современной педиатрии. 2013; 12 (1): 17-23. / Krasovskiy S.A., Nikonova V.S., Kashirskaya N.Yu. et al. Clinical, genetic, microbiological and functional parameters of patients with cystic fibrosis living in Moscow and Moscow region. Voprosy sovremennoy pediatrii. 2013; 12 (1): 17-23 (in Russian).

9. Godbout A., Hammana I., Potvin S. et al. No relationship between mean plasma glucose and glycated haemoglobin in patients with cystic fibrosis-related diabetes. Diabet. Metab. 2008; 34 (6, Pt 1): 568-573.

10. Tierney S., Webb K., Jones A. et al. Living with cystic fibrosis-related diabetes or type 1 diabetes mellitus: a comparative study exploring health-related quality of life and patients' reported experiences of hypoglycaemia. Chron. Illn. 2008; 4 (4): 278-288.

11. WHO. Diabetes Mellitus: Report of a WHO Study Group. Technical Report Series 727. Geneva, WHO, 1985.

12. The Expert Committee on the Diagnosis and Classification of Diabetes Mellitus: Report of the Expert Committee on the Diagnosis and Classification of Diabetes Mellitus. Diabet. Care. 1997; 20: 1183-1197.

13. Каширская Н.Ю. Состояние желудочно-кишечного тракта, поджелудочной железы и гепатобилиарной системы у больных муковисцидозом: Дис. ... д-ра мед. наук. M.; 2001. / Kashirskaya N.Yu. Digestive Tract, Pancreas and Hepatobiliary System in Patients with Cystic Fibrosis: Diss. [Sostoyanie zheludochno-kishechnogo trakta, podzheludochnoy zhelezy i gepatobiliarnoy sistemy u bol'nykh mukovistsidozom]. Moscow, 2001 (in Russian). 
14. Blackman S.M., Hsu S., Vanscoy L.L. et al. Genetic modifiers play a substantial role in diabetes complicating cystic fibrosis. J. Clin. Endocrinol. Metab. 2009; 94 (4): 1302-1309.

15. Tong Y., Lin Y., Zhang Y. et al. Association between TCF7L2 gene polymorphisms and susceptibility to type 2 diabetes mellitus: a large Human Genome Epidemiology (HuGE) review and meta-analysis. BMC Med. Genet. 2009; 10: 15.

16. Bodhini D., Radha V., Dhar M. et al. The $\operatorname{rs} 12255372(\mathrm{G} / \mathrm{T})$ and rs7903146(C/T) polymorphisms of the TCF7L2 gene are associated with type 2 diabetes mellitus in Asian Indians. Metabolism 2007; 56 (9): 1174-1178.

17. Finkelstein S.M., Wielinski C.L., Elliott G.R. et al. Diabetes mellitus associated with cystic fibrosis. J. Pediatr. 1988; 112 : 373-377.

18. Moran A., Diem P., Klein D.J. et al. Pancreatic endocrine function in cystic fibrosis. J. Pediatr. 1991; 118: 715-723.

19. Garagorri J.M., Rodriguez G., Ros L., Sanchez A. Early detection of impaired glucose tolerance in patients with cystic fibrosis and predisposition factors. J. Pediatr. Endocrinol. Metab. 2001; 14: 53-60.

20. Milla C.E., Warwick W.J., Moran A. Trends in pulmonary function in patients with cystic fibrosis correlate with the degree of glucose intolerance at baseline. Am. J. Respir. Crit. Care Med. 2000; 162: 891-895.

21. Yung B., Noormohamed F.H., Kemp M. et al. Cystic fibrosisrelated diabetes: the role of peripheral insulin resistance and beta-cell dysfunction. Diabet. Med. 2002; 19: 221-226.

22. Dobson L., Sheldon C.D., Hattersley A.T. Understanding cystic-fibrosis-related diabetes: best thought of as insulin deficiency? J. Roy. Soc. Med. 2004; 97 (Suppl. 44): 26-35.

23. Ali B.R. Is cystic fibrosis-related diabetes an apoptotic consequence of ER stress in pancreatic cells? Med. Hypothes. 2009; 72 (1): 55-57.

24. Самойленко В.А., Красовский С.А., Марченков Я.В. и др. Клинические особенности течения муковисцидоза у взрослых больных с нарушением углеводного обмена. Терапевтический архив. 2013; 3: 32-37. / Samoylenko V.A., Krasovskiy S.A., Marchenkov Ya.V. et al. Clinical features of cystic fibrosis in adults with carbohydrate meta- bolism disorders. Terapevticheskiy arkhiv. 2013; 3: 32-37 (in Russian).

25. Dobson L., Sheldon C.D., Hattersley A.T. Validation of interstitial fluid continuous glucose monitoring in cystic fibrosis. Diabetes Care 2003; 26: 1940-1941.

26. Florez J.C., Jablonski K. A., Bayley N. TCF7L2 polymorphisms and progression to diabetes in the diabetes prevention program. N. Engl. J. Med. 2006; 355 (3): 241-250.

27. Liu Z., Habener J. F. Glucagon-like peptide-1 activation of rCFZL2-dependent Wnt signaling enhances pancreatic beta cell proliferation. J. Biol. Chem. 2008; 283: 8723-8735.

28. Van Vliet-Ostaptchouk J. V. et al. Association of variants of transcription factor 7-like 2 (TCF7L2) with susceptibility to type 2 diabetes in the Dutch Breda cohort. Diabetologia 2007; 50 (1): 59-62.

29. Chandak G. R., Janipalli C.S., Bhaskar S. et al. Common variants in the TCF7L2 gene are strongly associated with type 2 diabetes mellitus in the Indian population. Diabetologia. 2007; 50 (1): 63-67.

30. Grant S.F., Thorleifsson G., Reynisdottir I. et al. Variant of transcription factor 7-like 2 (TCF7L2) gene confers risk of type 2 diabetes. Nature Genet. 2006; 38: 320-323.

\section{Информация об авторах}

Самойленко Виктор Александрович - научный сотрудник лаборатории муковисцидоза; тел.: (495) 465-74-15; e-mail: samoilenkov@mail.ru Петрова Ника Валентиновна - д. М. н., ведущий научный сотрудник лаборатории эпидемиологической генетики; тел.: (499) 320-60-90; e-mail: npetrova63@mail.ru

Бабаджанова Гульнара Юсуповна - д. м. н., зав. лабораторией генетики и мультифакториальных заболеваний; тел.: (495) 465-52-64; e-mail: babadjanova@rambler.ru

Нагорный Александр Борисович - к. м. н., научный сотрудник лаборатории генетики и мультифакториальных заболеваний; тел.: (495) 465-52-64; e-mail: alnagor@mail.ru

Красовский Станислав Александрович - к. м. н., научный сотрудник лаборатории муковисцидоза ФГБУ "НИИ пульмонологии" ФМБА России; тел.: (495) 465-74-15; e-mail: sa_krasovsky@mail.ru

Чучалин Александр Григорьевич - Д. М. Н., профессор, директор ФГу "НИИ пульмонологии" ФМБА России; тел. / Факс: (495) 465-52-64; e-mail: chuchalin@inbox.ru 